\title{
AEROMAGNETIC MAP OF PART OF KENT COUNTY, MARYLAND, AND PARTS OF ADJACENT COUNTIES IN MARYLAND AND DELAWARE
}

\author{
GEOPHYSICAL INVESTIGATIONS \\ MAP GP-756
}

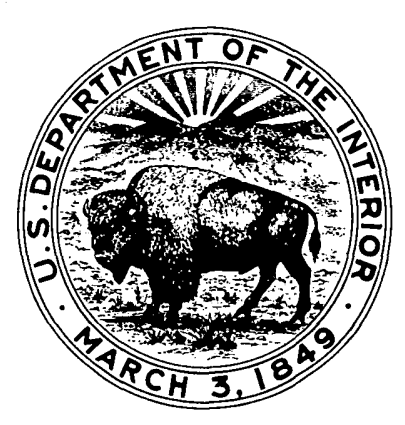

PUBLISHED BY THE U.S. GEOLOGICAL SURVEY 